\title{
Vertical transmission of dengue haemorrhagic fever; anticipation and early detection leading to success in management
}

\author{
Sinhabahu VP' ${ }^{1}$, De Silva MLK ${ }^{2}$, Sanjeewa MAGA ${ }^{2}$ \\ ${ }^{\prime}$ Teaching Hospital Mahamodara, Galle, Sri Lanka. \\ ${ }^{2}$ Lady Ridgeway Hospital for Children, Colombo, Sri Lanka.
}

\author{
Correspondence: Dr. V P Sinhabahu \\ e-mail:sinbad.lk@gmail.com \\ https://orcid.org/0000-0003-0065-2845
}

:

\section{Introduction}

Dengue is a vector borne disease responsible for nearly 4 billion infections annually, prevalent in the tropics with seasonal outbreaks (1). Aedes spp. act as the vector (1). There were 105,049 cases of dengue reported in Sri Lanka in 2019 (2). Neonatal dengue infection can result from vertical transmission through placenta (3). We report a case of a newborn with dengue haemorrhagic fever due to vertical transmission. Anticipation and early detection was the key to successful management.

\section{Case presentation}

A baby girl was born by vaginal delivery to a primigravida mother with dengue fever at 38 weeks of gestation. She weighed $2300 \mathrm{~g}$ at birth. Antenatal period was uncomplicated except maternal fever which developed 2 days prior to the delivery. Mother's febrile illness was initially managed as dengue fever (DF) and it was subsequently progressed to dengue haemorrhagic fever (DHF). She was managed in an intensive care unit where she gave birth. The baby was immediately admitted to the Special Care Baby Unit (SCBU) following birth for observation with the suspicion of vertical transmission of dengue. In baby's blood, NS1 antigen was negative on day 2 but become positive on day 4 . Ultrasound scan (USS) of abdomen and thorax did not show evidence of leaking on day 4. Results of serial haematological investigations are shown below (Table 1). Baby was fed with expressed breast milk from day 2 of life and started on prophylactic antibiotics; intravenous crystalline penicillin and cefotaxime on day 4 .
She developed a significant drop in platelet count down to $58,000 / \mathrm{mm}^{3}$ with a rise of total white cell count on $5^{\text {th }}$ day. Repeat USS of abdomen and thorax on day 5 showed pericholecystic fluid and pericardial effusion confirming the diagnosis of DHF (Figures 1 and 2). She was managed as leaking phase of DHF from day 5 with fluid management and monitoring of haemodynamic parameters (pulse rate, blood pressure, capillary refilling time, urine output). She was given maintenance fluid intravenously according to the day of life starting with $60 \mathrm{ml} / \mathrm{kg}$ in day 1 . Maintenance fluid was increased $15 \mathrm{ml} / \mathrm{kg}$ per day till day 7. Urine output was measured and targeted to keep above $1 \mathrm{ml} / \mathrm{kg} /$ hour. Urine output and haemodynamic parameters were used to guide the fluid management. A cocktail mixture of fluids with sodium $2-3 \mathrm{mmol} / \mathrm{kg}$, potassium $1-2 \mathrm{mmol} / \mathrm{kg}$ and $5 \%$ dextrose was used as intravenous fluids from day 2. Our patient did not need any fluid boluses. Microhaemaocrit centrifugers to measure packed cell volume (PCV) were not available in the hospital. Hence the measurement of PCV frequently was not possible. Oozing from puncture sites was noted on day 7 which settled subsequently. No other bleeding manifestations were noted. Platelet count started to rise on day 7 indicating the beginning of the recovery phase of DHF. Baby's haemodynamic parameters were stable throughout the leaking phase. DEN 3 virus was isolated in a blood sample obtained on day 5 of life by Reverse Transcriptase - Polymerase Chain Reaction (RT PCR). Mother also had DEN 3 virus isolated in her blood in day 7 of her illness. Baby did not have 
Table 1: Serial haematological investigations of the newborn

\begin{tabular}{|c|c|c|c|c|c|c|c|c|c|c|c|c|}
\hline \multirow[t]{2}{*}{ Age in days } & Day & Day & Day & Day & Day & Day & Day & Day & Day & Day & Day & Day \\
\hline & $\mathbf{0}$ & 1 & 2 & 4 & 5 & 5.5 & 6 & 6.5 & 7 & 7.5 & 8 & 8.5 \\
\hline $\mathrm{WBC}\left(/ \mathrm{mm}^{-3}\right)$ & 11840 & 22580 & 17980 & 12740 & 9000 & 6250 & 8500 & 11520 & 11600 & 10710 & 15560 & 18010 \\
\hline Neutrophils $\left(/ \mathrm{mm}^{-3}\right)$ & 7340 & 17160 & 9277 & 7886 & 5640 & 4000 & 3910 & 4147 & 3132 & 3160 & 5240 & 5170 \\
\hline Lymphocytes $\left(/ \mathrm{mm}^{-3}\right)$ & 2960 & 3297 & 6724 & 3491 & 999 & 1375 & 3145 & 5299 & 6612 & 6051 & 8520 & 9220 \\
\hline $\mathrm{Hb}(\mathrm{g} / \mathrm{dL})$ & 14.2 & 15.7 & 14.8 & 12.5 & 12.4 & 12.9 & 13.4 & 13.3 & 14.0 & 12.8 & 12.3 & 13.0 \\
\hline Haematocrit (\%) & 45 & 50.4 & 48.9 & 39.2 & 39.2 & 40.2 & 42.3 & 40.6 & 43.1 & 40.4 & 38.6 & 39.7 \\
\hline Plt count $\left(\times 10^{3} / \mathrm{mm}^{3}\right)$ & 253 & 309 & 231 & 372 & 204 & 184 & 114 & 58 & 48 & 39 & 54 & 64 \\
\hline $\operatorname{ALT}(\mathrm{U} / \mathrm{L})$ & 11 & & & & & & & & 34 & & & \\
\hline AST (U/L) & 97 & & & & & & & & 204 & & & \\
\hline
\end{tabular}

$\mathrm{Hb}$ - Haemoglobin, Plt. - Platelet, ALT - Alanine Aminotransferace, AST - Aspartate Aminotransferace

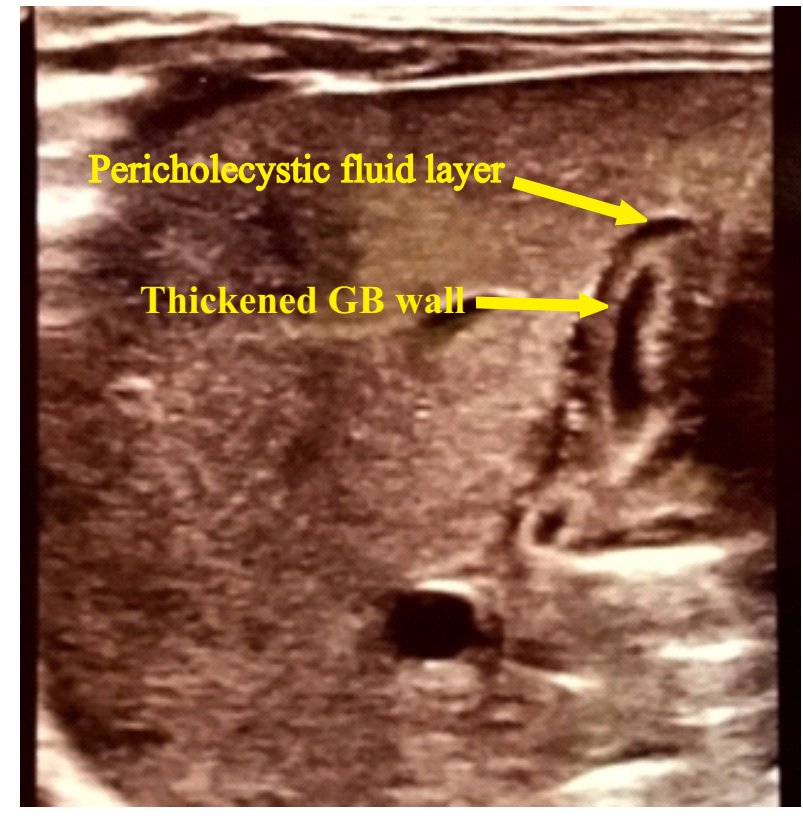

Figure 1: USS Abdomen showing pericheolestatic fluid

Dengue antibodies were done on day 7 of life and showed dengue IgM positive with IgG negative. Mother's dengue IgG and IgM both were positive on day 9 of her illness.

Baby recovered fully from the illness without any complications.

\section{Discussion}

Vertical transmission of dengue could occur transplacentally or via breast milk. Transplacental transmission of dengue virus can occur in late

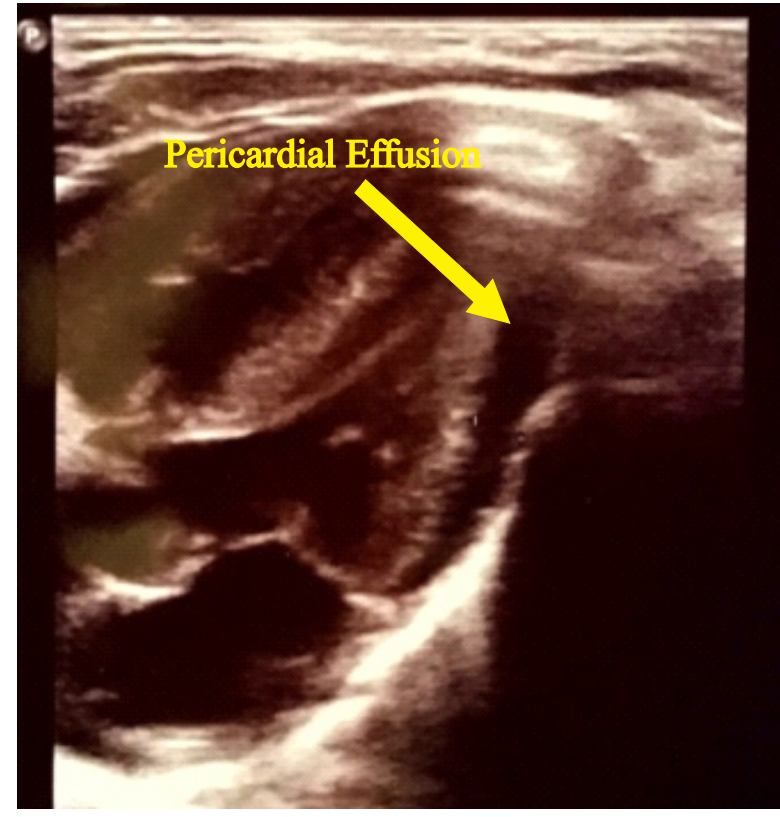

Figure 2: USS Thorax with evidence of pericardial effusion

pregnancy (3). A study in New Caledonia showed a vertical transmission rate of $90 \%$ in the perinatal period in mothers who had dengue fever close to delivery and dengue virus was detected in breast milk in $75 \%$ of breast feeding mothers with DF (4). As this baby was taken into SCBU following birth, it was highly unlikely to have a mosquito bite. Hence, vertical transmission was the only possible mode of transmission. It was not possible to conclude whether mother had primary or secondary dengue infection. 
SD BIOLINE Dengue NS1 antigen rapid test which was used to detect NS1 antigen has a specificity of $98.3 \%$ and sensitivity of $76.7 \%$ (5). Dengue RT-PCR was used to detect dengue virus in blood of mother and baby. It revealed the same serotype. NS 1 antigen was not detected in day 2 but was positive on day 4. Breastfeeding was started on day 2. It was possible to have vertical transmission either transplacentally or via breast milk. We could not perform dengue RT-PCR on cord blood which might have been helped to confirm transplacental transmission.

A marked drop in the platelet count and an increase in the dropping of the WBC count were noted during the onset of leaking which occurred on day 6 of life. Subsequent USS confirmed leaking. Lack of guidelines to manage neonates with DHF and unavailability of microhaematocrit measurements were challenges in the management. Monitoring the vital parameters and trends of $\mathrm{WBC}$ and platelets were important to monitor the clinical course of DHF.

A review of 17 neonates with vertical transmission of DF showed fever occurring from day 1 - 11 of life with a median on day 4 (6). There are neonatal dengue cases reported in South Asian region including Sri Lanka and rest of the world (7-9). Most neonates recover without complications. Awareness of the possibility of vertical transmission of DF was very important as our patient never had fever during the course of the illness.

DENV- 1 and DENV- 3 serotypes of dengue virus are known to cause DHF on primary dengue infection (9). DENV -3 was isolated in our patient.

Management of neonate with DHF is challenging. Early suspicion of vertical transmission, SCBU care with continuous monitoring and fluid management leads to the successful outcome in our patient. Further studies on the possibility of transmission of dengue via breast milk are needed. A guideline on management of DHF in neonates will be helpful.

\section{Acknowledgements}

We would like to thank the staff of Department of Virology at Teaching Hospital Karapitiya and Medical Research Institute.

\section{References}

1. Moi ML, Takasaki T. Rinsho Byori. 2016; 64(9): 1033-43. Accessed on 03.09.2020

2. Epidemiology Unit, Ministry of Health, Sri Lanka. http://www.epid.gov.lk/web/index.php?option=com_con tent\&view=article\&id=171\%3Adengue-update \&catid $=51 \% 3$ Amessage-for-public \&Itemid=487\&lang=en. Accessed on 08.09.2020

3. Wiwanitkit V. Unusual Mode of Transmission of Dengue. The Journal of Infection in Developing Countries, 2009; 4(1): 51-54. DOI: 10.3855/Jiddah.145.

4. Arragain L, Dupont-Rouzeyrol M, 'OConnor O, Sigur N, Grangeon JP, Huguon E, et al. Vertical Transmission of Dengue Virus in the Peripartum Period and Viral Kinetics in Newborns and Breast Milk: New Data. Journal of the Pediatric Infectious Disease Society, 2017; 6(4): 324-31. DOI: $10.1093 / /$ jpids/piw058. Accessed on 03.08.2020. https://www.ncbi.nlm.nih.gov/pubmed/27760799.

5. Wang SK, Sekaran SD, Evaluation of a Commercial SD Dengue Virus NS1 Antigen Capture Enzyme-Linked Immunosorbent Assay Kit for Early Diagnosis of Dengue Virus Infection. Journal of Clinical Microbiology, 2010; 48(8): 2793-2797. DOI: 10.1128/JCM.02142-09 viewed in https://jcm.asm.org/content/48/8/2793. Accessed on .

6. Sirinavin S, Nuntnarumit P, Supapannachart S, Boonkasidecha S, Techasaensiri C, Yoksarn S. Vertical dengue infection: case reports and review. The Pediatric Infectious Disease Journal, 2004; 23(11): 1042-7. Viewed in https://www.ncbi.nlm.nih.gov/pubmed/15545860. Accessed on 03.08.2019.

7. Keerthy S, Nagesh K. Are we Missing Neonatal Dengue? Indian Pediatrics, 2019; 56(8): 697 viewed in https://www.indianpediatrics.net/aug2019/697.pdf. Accessed on 23.08.2020.

8. Gamhewage NC, Weerasekara M, Nazmy MHM. Vertically transmitted dengue in a neonate born to a mother with asymptomatic dengue infection. Sri Lanka Journal of Child Health, 2019; 48(2): 168-9.

9. Maroun SL, Marliere RC, Barcellus RC, Barbosa CN, Ramos JR, Moreira ME. Case report: vertical dengue infection. J Pediatr (Rio J), 2008; 84(6): 556-9. DOI: 10.2223/JPED.1826.

10. Sellahewa KH. Pathogenesis of Dengue Haemorrhagic Fever and Its Impact on Case Management. ISRN Infectious Diseases, 2013: Article ID 571646, 6 pages. https://doi.org/10.5402/2013/571646. 